\title{
Impact of Multicultural Environment of Islamic Educational Institutes on Students' Acculturation
}

\author{
Yousef Rahath House, Mohd Abbas Abdul Razak, and Hiba Ashraf
}

\begin{abstract}
The study focuses on the effect of exposure to Multicultural and international environment of an Islamic educational institution on the acculturation of its students. Acculturation has been used in this study with a wide sense of meaning that underscores the sense of co-existence and feeling of unity. This study investigated whether the Internationalization process of the International Islamic University, Malaysia, with intergroup contact taking place under optimal conditions helps its students to, appreciate the differences that other cultures bring, be comfortable with differences and also seek diversity of contact. The study employed Miville-Guzman Universality - Diversity Scale, (M-GUDS-S) to collect data by survey method from 400 IIUM undergraduate students selected using Quota sampling. 200 of them were the first year students and the rest were fourth-year students. The result showed that there is a significant improvement in the feeling of unity among the students. The fourth year students showed more appreciation for other cultures and comfort with differences. Based on the finding it has been suggested that if efforts are made to establish optimal conditions for positive intergroup contact to take place, intergroup prejudice can be reduced and problems of co-existence in the Muslim countries and communities can thus be addressed.
\end{abstract}

Index Terms-Appreciation of other cultures, comfort with differences, diversity of contact, intergroup contact, Multicultural environment, unity feeling, prejudice.

\section{INTRODUCTION}

The present day scenario calls for a universal community where, everything including personal relations, have become inter-racial, inter-cultural and inter-religious. Due to the migration of people in search of jobs, better livelihood, family, education, as a result of the war, civil and economic crisis in their own countries it has now become impossible to live in a society whose members belongs to just one culture, ethnic group, religion or religious group. This situation has incited discussions, studies, and research that focus on how unity and peaceful coexistence can be brought within such diversity and differences. In the Muslim context this issue is very relevant due to the problems faced by the Muslim communities. Although from the Islamic literature it can be seen that Islam upholds pluralism and encourages unity and peaceful coexistence in a multicultural environment, the contemporary picture of Islamic societies is quite

Manuscript received June 14, 2016; revised August 12, 2016. This work was supported by the Research Management Center International Islamic University Malaysia under the grant EDW B14-169-1054.

The authors are with the Department of Social Foundations and Educational Leadership, International Islamic University Malaysia, Malaysia (e-mail: yusufrahathr@gmail.com, maarji@iium.edu.my, hiba_kakkat@yahoo.com). contradictory to this teaching of Islam. From this it can be understood that despite the fact that Muslim scholarship accepts and agrees with the theoretical interpretation of Islam on unity, this interpretation fails to materialise in practical settings. Meaning that this teaching of Islam can be seen only in theory. When it comes to making it practical and possible, the contemporary Muslim world has not been very successful.

Taking this issue into consideration it might be helpful to take into consideration some of the existing studies that addresses the issues of diversity in the modern society. Some writers have suggested the importance of intergroup contact as a solution to addressing the problems of diversity in a community [1]-[6]. Based on these studies it can be observed that just the theoretical teachings of tolerance are not sufficient in reducing prejudice or inculcating a feeling of unity within a community. But at the same time, the communities must also get the opportunities to experience and interact with different people that come from various socio-cultural backgrounds to make it possible. In other words, a conscious effort to create a better intergroup contact is one of the best solutions of the practical manifestation of the theory of unity that any ideology upholds.

In line with this view, various researchers have carried out several studies in different contexts. Among these some of them have claimed that creating a positive intergroup contact context is one of the best solutions that can be used to have positive effects on reducing prejudice and discrimination and promoting tolerance among the members of different groups [7]. According to intergroup contact theory, contact between members belonging to diverse groups under optimal conditions leads to a reduction in prejudice among them [8]. Here the emphasis is given to good quality contact taking place under optimal conditions. In an environment where people belonging to different groups coexist, engage in some or the other form of contact is inevitable. While making use of public systems and facilities, shopping etc. members of different groups living in a community are bound to come into contact. But such casual contact is not what intergroup contact theory suggests. Here the important factor is that the contact should take place under optimal conditions. By optimal conditions, it means that for intergroup contact to have positive effects it should take place in a situation where there exists equal status between groups. In other words, the contact should take place in a condition where the members of the groups share equal rights and positions and that no group should have any superiority, dominance or advantage over the other groups, whether legally, socially or culturally.

In line with this, the concept of cultural symbiosis as presented by Bakar [9] provides a model of reducing prejudice through intergroup contact. Cultural symbiosis is 
defined by him as "the intimate living together of two or more cultural entities on the basis of mutual interdependence" [9]. According to him the first step in achieving cultural symbiosis is mutual contact and acquaintance. Only when one meets and interacts with another can one know the other. If this is pursued, it may lead to mutual understanding and co-operation and help. This will, in turn, lead to tolerance. This acquaintance according to him needs to be cultivated in a healthy, pleasant and calm atmosphere. One must also have well-ordered priorities to cater for the common interest of the parties involved. Simultaneously, the mutual acquaintance and contact go from the acceptance of physical characteristics to the understanding of psychological mind-set which in turn leads to acquiring manners and customs acceptable to both cultures [9].

\section{FEELING OF UNITy AND UNIVERSAL DiVERSITY ORIENTATION}

From the above discussions, it is clear that engaging in quality intergroup contact is important and it can be seen that this more often leads to the development of qualities that are essential for bringing about a feeling of unity. So, taking this analysis into consideration, it can be argued that people living in an environment of positive intergroup contact must have developed a feeling of unity. However, here the question arises of how it can be shown that unity feeling has been developed or in other words how the feeling of unity can be measured. Some studies have presented models that can be used in this study to examine the existence of unity feeling among people. Miville's 'Universal Diversity Orientation' (UDO) construct and the related scale MGUDS [10] is one of the suitable scales that can be used to measure unity feeling because the MGDUS measures acculturation or unity feeling that is the central theme of this research.

According to this construct, three components play an important role in being able to accept differences and similarities between people and in fostering a feeling of unity. These components represent the cognitive, behavioural and emotional aspects of engaging in intergroup contact. They are relativistic appreciation, diversity of contact and comfort with differences.

Relativistic appreciation: This is the cognitive component. According to this component, a person with UDO will value the differences and similarities among others and himself [10]. Along with that, he will be able to appreciate the impact such diversity of contact on his personal growth and self-understanding. A person with such an attitude and awareness will not see diversity or differences as negative. On the other hand, he will be able to welcome differences as necessary for his development.

Seeking diversity of contact: This represents the behavioural component of this construct. Because a person values the impact of differences brought in by diverse groups he will seek to engage in a diversity of contact. He will show an interest in interpersonal contact with people of different race, gender, religion and other demographic background and be attending programmes, functions, talks or other such opportunities that would give him the opportunity for gaining a diversity of experiences.

Comfort with differences: This is the emotional component. According to this construct a person with UDO forms a sense of connection with members of diverse groups as a result of contact with them. this reinforces further contact. Building close friendships with diverse people, working together with people from different background, engaging in projects works and so on are examples of how such emotional connections can be formed and be generalised to other members of those groups to which these members belong.

Hence, analysing if engaging in positive intergroup contact has developed a feeling of unity, can be done by examining if they appreciate differences, are comfortable with differences and whether they are willing to seek diversity of contact as a result of engaging in intergroup contact. In other words, the MGDUS scale that assesses these aspects of universal diversity orientation can be used to answer the major question raised in this study: Does positive intergroup contact result in the development unity feeling? The subscales of the MGDUS scale will also help in answering other questions raised in this study: Does the opportunity for positive intergroup contact fosters appreciation of other cultures/communities? Does it lead to being more comfortable with differences among themselves? And does the experience of positive intergroup contact and universality/similarity encourage the students to seek diversity of contact?

\section{FEELING OF UNITY AMONG MUSLIMS LIVING IN AN ENVIRONMENT OF POSITIVE INTERGROUP CONTACT}

\section{A. Research Site}

To analyse if a feeling of unity exists among Muslims an analysis should be done on Muslims living in a multicultural setting where positive intergroup contact takes place. For this analysis International Islamic University Malaysia has been taken as the research site. An International educational institution was chosen because educational institutes are good examples of places where people are forced to interact with members or other cultures and races.

An educational institution was chosen because educational institutions are among the most important settings in which the next generation has the opportunity to develop positive attitudes towards other groups (Jones, 1994). Hence, they can be a very fertile ground to widen horizons, foster a sense of understanding and tolerance and also reduce prejudice and discrimination among its students. Further, according to some educational theorists, one of the major functions of educational institutions is to inculcate the feeling of unity and social solidarity. So, the presence of quality of intergroup contact at an educational institute is an obvious reality.

\section{B. Participants}

400 undergraduate students of IIUM participated in this study. The students were from diverse cultural and national backgrounds. Among the 400 participants 200 were first-year students and 200 were fourth year students. The first year students served as the control group and the fourth year 
students as the experimental group due to their exposure to the internationalisation process of IIUM for four years. The fourth year students have thus had more opportunities for positive intergroup contact. Hence, it is hypothesised that feeling of unity will be higher among the fourth year students compared to the first year students. It is also hypothesised that the fourth year students will be more appreciative of and comfortable with differences, and will be more interested in seeking diversity of contact compared to first year students.

\section{Research Instrument}

For the purpose of this research, a modified version of Miville-Guzman Universality-Diversity Scale (M-GUDS) [10] was used. It is a self-reported instrument which is used to measure the universal-diverse orientation (UDO) of the respondents. The attitude of awareness and acceptance of similarities and differences is reflected by this construct. It is a 45 item scale that uses a6 point Likert-type scale and has 3 subscales. They are; 1) Diversity of contact 2) Relativistic appreciation 3) Comfort with differences/ sense of connection. Slight modifications were made to the instrument to suit the objectives and purposes of this study. The instrument was reported to have high reliability and validity rate by various studies [10], [12]-[13]. It was shown to have a high internal consistency and test-retest reliability ranging from 0.89 to 0.95 [13]. To test its reliability in the present setting a pilot test using 30 participants was conducted and the results indicated a relatively high-reliability rate of 0.76 .

\section{RESULT}

As was hypothesised, an independent sample t-test revealed that there was a significant difference is the level of feeling of unity between the first year and fourth year students, with the fourth year students showing a higher level of level of feeling of unity $t(199)=2679, p(0.008)<0.05$. The results clearly indicated that exposure to intergroup contact at the multicultural environment of IIUM leads to the development of unity feeling among its students. The fourth year students showed a significantly higher appreciation of oneself and others compared to the first year students; $t(199)=3.498, \mathrm{p}(0.001)<0.05$. Similar results were also observed in the analysis of scores of the comfort with differences subscale. The fourth year students were observed to be more comfortable in dealing with individuals from diverse backgrounds compared to the first year students; $t(199)=2.155, p(0.032)<0.05$. However, analysis of the scores of the diversity of contact subscale differed from the above results. The independent sample t-test showed that there was no significant difference between the first year and fourth year students in terms of seeking diversity of contact; $t(199), p(0.141)>0.05$.

\section{DISCUSSION}

In light of the present condition of the Muslim community, the objective of this study was to analyse if engaging in positive intergroup contact in a Muslim Education setting, where students are forced to engage in intergroup contact under optimal conditions, would lead to the development of unity feeling. The result indicated that intergroup contact under optimal conditions does have a positive impact. This is in line with Tropp's [8] intergroup contact theory. Intergroup contact reduces prejudice and helps the students to tolerate and also appreciate differences.

In encouraging and facilitating the development of friendships between different groups by making the students work in teams consisting members of diverse backgrounds, making sure students get the opportunity to share classes and hostel rooms with students from different background and organising programmes where students from diverse background work together, positive intergroup contact was ensured. And favourable results were observed.

The students' appreciation for other cultures and communities implies that they value the impact intergroup contact has on their personal growth and self-understanding [14]. An increase in the degree of comfort in dealing with students from diverse backgrounds, who are different from them, indicates that the students develop an appreciation and are not disturbed by the differences and similarities in other students that are different from them [14].

However, although the endeavours on the part of the university have had a positive impact on the students' development of unity feeling, it can be seen from the results that the students failed to show an increase in seeking diversity of contact as a result of their intergroup contact. This is of concern because it is the 'seeking diversity of contact' subscale that measures the behavioural component of the MGDUS. The students' response to this subscale indicates that they do not show an increased interest in participating in cultural and social activities of diverse groups as a result of the multicultural environment they are in. Although intergroup contact is said to have a positive impact on the students, they do not take the extra initiative to establish intergroup contact.

Preferring to engage in contact with members of one's own culture and community is a natural observable fact as far as human beings are concerned. Ibn Khaldun's [15] concept of asabiyyah explains this aspect of human nature. Asabiyyah according to him is an important principle required for the survival, development and sustenance of a community or a nation. It is the sense of belonging that the people of that community or particular group have which prompt them to collectively strive for their development and establishment. The concept of seeking diversity of contact does not mean to undermine this aspect of humans' social nature. But at the same time, the importance of diversity of contact needs to be realised as diversity contributes personal growth and self-understanding [10].

Another important factor that needs to be realised is that being a Muslim, one's feeling of assabiyyah should not just confine to one's own nation or culture. It should extend to religion as well. According to Ibn Khaldun [15], the feeling of solidarity among the members of a religious group is important for that religion to succeed and be effective. So apart from solidarity with one's own nation or race or sect or religious subdivision, their feeling of solidarity should ultimately be towards Islam. This being the case, although the students belong to different nations, cultures, religious subdivisions, there should be an attempt on their part to work 
towards bridging the gap created by these differences and unite in the feeling of solidarity with Islam; their common religion. It is only by overcoming divisions within themselves that they will be able to extend their feeling of unity towards others.

As opposed to the meaning in which the concept of assabiyyah has been used here, it has been used in a negative sense to indicate blind partiality towards a particular group even in the face of contradictions or unacceptable approaches and sometimes out groups is demoralised and denounced. This is against the spirit of Islam. Being a vicegerent of Allah on earth Muslims are expected to have a feeling of responsibility towards all human beings (and creatures), irrespective of their religion, race, culture and so on. As the Qur'an says in Surah Baqarah, 143 " We have made of you an ummah justly balanced, that you might be witnesses over the nations..." [16].

Thus, although focus should be given to bringing about a feeling of unity among the Muslims, community feeling should also focus on universal factors like being a human. The distinction that comes within that universality should be one that is appreciated and seen as crucial for mutual growth and development and not discriminated against.

In essence, engaging in intergroup contact is what will help in the development of this sense of understanding and connection among people. For this students should be able to overcome their passivity and develop a sense of purpose. Taking an initiative in establishing contact with people different from oneself requires that a person is dynamic and vibrant and be with a sense of purpose. It is the sense of purpose and a common goal to work towards that can bring people together and bond them as one. In Allport's [17] four primary conditions that a contact situation should embody, having a common goal is an important condition. Efforts should be taken in this direction.

Since the multicultural environment has succeeded in fostering among the students the cognitive and affective components, the development of the related behavioural component is relatively uncomplicated. Thus, efforts should be made to inculcate among the students a sense of assabiyyah towards the Muslim community as a whole which would enable them to form a bond of solidarity. Efforts should also be made to instil in them a sense of purpose and a common goal of developing the Muslim community to make them more dynamic and vibrant. In doing so the differences students from different countries, communities, race and religious backgrounds bring, should not be ignored or suppressed. Instead, efforts should be made to help them develop and be confident of their own identity. Because it is people that are confident about their identity and uniqueness and realise that diversity actually may contribute to self-development and development of creativity are encouraged to seek diversity of contact [18].

\section{CONCLUSION}

It was seen that if efforts are made to bring about positive intergroup contact under optimal conditions, intergroup prejudice can be reduced. Problems in the Muslim countries and communities can thus be addressed to an extent if they take the initiative to establish optimal conditions for positive intergroup contact to take place. This includes bringing about an environment of positive interactions, amending laws and rules that promote discrimination against the minorities, foreigners and members of other groups.

In this respect, one of the main problems that need to be addressed in many Muslim countries is their approach to immigrants and the minority population of their countries. The GCC nations are home to about 15 million immigrants, of which most are Muslims and from the south Asian countries [19]. But, although conditions are improving, unfortunately, some of these courtiers still have no proper working conditions, healthcare and housing facilities. In addition to this, the immigrants and foreigners suffer from inferior status and sometimes inhumane treatment. Their conditions are further aggravated by lack of labour laws in some of these countries. There can also be seen discrimination in wages of the employees according to the nationality or racial background of the person.

Such conditions only increase the possibility of discrimination and prejudice among people. Hence, a change from this is crucial. More efforts should be made by the government of Muslim countries to establish equal status between groups, bring them together with common goals and also provide avenues for intergroup contact and cooperation among different groups to take place. Any form of discrimination and unfair treatment should not be tolerated.

A step that can be taken in this direction is to have educational institutions that bring together people from different communities. This will provide an opportunity for students to engage in positive intergroup contact with students from a diverse background from a very young age. Similarly, establishing institutions that are open to different groups of the society; bringing together people from the different background into the workforce based on their ability and talent rather than their nationality and providing optimal conditions for them to work together, are some of the means by which positive intergroup contact can be ensured. Taking necessary steps in this manner is crucial to the development and coexistence of a multicultural community and developing among people a feeling of unity.

\section{REFERENCES}

[1] A. Adesokan, J. Ullrich, R. Dick, and L.R. Tropp, "Diversity beliefs as moderator of the contact-prejudice relationship," Social Psychology, vol. 42, no. 4, pp. 271-278, 2011

[2] N. Bikmen, "Asymmetrical effects of contact between minority groups: Asian and black students in a small college," Cultural Diversity and Ethnic Minority Psychology, vol. 17, no. 2, pp. 186-194, 2011.

[3] G. Katy, and B. Rupert, "Acculturation and contact in Japanese students studying in the United Kingdom," The Journal of Social Psychology, vol. 145, no. 4. pp. 373-389, 2005.

[4] S. Nazanin, A. Joy, R. Daryl, and T. Rozalin, "The relationship of religious self-identification to cultural adaptation among Iranian immigrants and first-generation Iranians," Professional Psychology: Research and Practice, vol. 43, no. 4. pp. 328-335, 2012.

[5] C. T. Tadmor, Y. Y. Hong, M. M. Chao, F. Wiruchnipawan, and W. Wang, "Multicultural experiences reduce intergroup bias through epistemic unfreezing," Journal of Personality and Social Psychology, vol. 103, no. 5, pp. 750-772, 2012.

[6] P. Tummala-Narra and M. Claudius, "A qualitative examination of Muslim graduates International students' experiences in the United States," International Perspectives in Psychology: Research, Practice, Consultation, vol. 2, no. 2. pp. 132-147, 2013. 
[7] T. F. Pettigrew and L. R. Tropp, "How does intergroup contact reduce prejudice? Meta-analytic tests of three mediators," European Journal of Social Psychology, vol. 38, pp. 922-934, 2008.

[8] L. R. Tropp, "Intergroup contact theory," in Encyclopedia of Peace Psychology, D. J. Christie, Ed. Hoboken, NJ: Wiley-Blackwell Publishers, 2011.

[9] O. Bakar, "Cultural symbiosis and the role of religion in the contemporary world: An Islamic perspective," KATHA-The Official Journal of the Centre for Civilisational Dialogue, vol. 4, pp. 31-52, 2008.

[10] M. L. Miville, C. J. Gelso, R. Pannu, W. Liu, P. Touradji, P. Holloway et al, "Appreciating similarities and valuing differences: The Miville-Guzman Universality-Diversity Scale," Journal of Counseling Psychology, vol. 46, no. 3, pp. 291-307, 1999.

[11] J. M. Jones, "Our similarities are different: Toward a psychology of human diversity," in Human Diversity: Perspectives on People in Context, E. J. Trickett, R. J. Watts, and D. Birman Eds. Minneapolis, MN: University of Minnesota Press, 1994, pp. 27-48.

[12] G. C. Gamst, C. T. Liang, and A. Der-Karabetian, A. Handbook of Multicultural Measures, California, USA.: SAGA Publications Inc, 2011.

[13] M. D. Wilson, Improving Intergroup Relations Through Programmed Intergroup Contact: A Model Process and its Effects, United States: ProQuest LLC, 2006.

[14] T. Bhaskar, "Assessing effectiveness of multicultural readings in increasing ethnocultural empathy for undergraduate students," Ph.D. dissertation, University of Tennessee., 2011.

[15] Ibn Khaldun, The Muqaddimah: An Introduction to History, N. Dawood, Ed. F. Rosenthal, Trans. New York: Princeton, 1967.

[16] A. Y. Ali, The Holy Qur'antext and Translation, Kuala Lumpur.: Islamic Book Trust, 2007.

[17] G. W. Allport, The Nature of Prejudice, Cambridge/Reading, MA: Addison-Wesley, 1954.

[18] S. Carpenter, A. Garza, and M. A. Zarate, Cultural pluralism and prejudice reduction, Cultural Diversity and Ethnic Minority Psychology, vol. 13, no. 2, pp. 83-93, 2007.

[19] J. Glazov. (9 July 2012). The Exploitation of Immigrant Workers in the Middle East. Frontpage Magazine. [Online]. Available: http;//www.frontpagemag.com/fpm/137063/exploitation-immigrant-w orkers-middle-east-jamie-glazov.

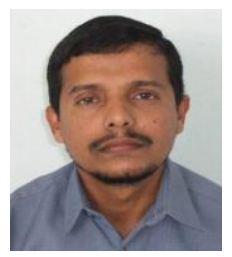

Yousef Rahath House graduated from University of Calicut, Kerala, India in 1991 with a double degree in B.A. History and B.A. Arabic. Simultaneously he also obtained a bachelor degree in Islamic History \& Civilization from Islahiya College, Kerala, India. He obtained his Master degree in M.A. Sociology and M.A. Arabic from the University of Calicut (India). His $\mathrm{PhD}$ was in the field of educational foundations

from IIUM in 2011

He worked as a junior lecturer for three years before joining as Executive Editor of a leading Malayalam magazine. He then joined as the college principal at Irshadiya college. During his studies at IIUM he worked as part time lecturer and later as a post doctoral research fellow. After obtaining his $\mathrm{Ph} . \mathrm{D}$ he was appointed as Assistant professor at the Department of Social Foundation \& Educational Leadership, Kulliyah of Education, International Islamic University, Malaysia (IIUM) where he currently works.

He has published numerous articles and conference papers. His research has been in the areas of social foundations, educational theories and philosophies. Some of his papers are; Contemporary Islamic Educational Discourse and the Philosophy of Empowerment, Education as an Agent of Empowering People to Act in and on the World, An Alternative Educational Approach to Make Muslim Youth Transformative Intellectuals.

Dr. Yousef is the Directorate Board Member of Ideal Publication Trust; Publisher of Madhyamam (The Media) Daily, a news paper published from Kerala and from Bahrain, Qatar, Kuwait and Dubai in regional language (Malayalam). He is also a Member of various Islamic Educational Board in
Kerala, India

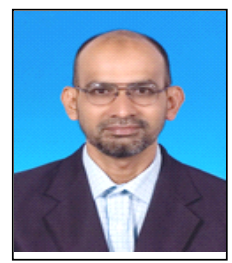

Mohd Abbas Abdul Razak obtained his B.A (Hons) degree from Universitas Ar-Raniry, Aceh, Indonesia in Islamic Education. Upon completing his undergraduate studies, Abbas returned to Malaysia in January 1992 and was teaching for a little while in the northern region of the peninsular of Malaysia before he went on to do his postgraduate studies at IIUM.

Over at IIUM, Abbas did his Advanced Diploma in Education and later went on to pursue his Ph.D. in the area of Educational Psychology. His Ph.D. dissertation was a study on personality theories, particularly comparing on the views showcased to the world by Iqbal and Freud. This research work of Abbas was later published as a book entitled 'Iqbal's Theory of Personality: A Contrastive Analysis with Freud' by LAP Lambert Academic Publishing of Germany. In 2010, he was teaching Philosophy of Islamic Education, Ethics \& Sociology of Education at the Kulliyyah of Education, IIUM.

Upon completing his Ph. D. in 2011, Abbas was appointed as an Assistant Professor at the Department of Fundamental \& Inter-Disciplinary Studies, KIRKHS, IIUM. He teaches all the university required courses; Islamic Worldview, Knowledge \& Civilization in Islam and Ethics and Fiqh for Daily Life. At times he also teaches psychology at the Kulliyyah of Education, IIUM

Besides teaching, Abbas also actively participates in many international conferences and in research works on psychology and Iqbaliyat. His research works has enabled Abbas to publish quite a number of articles related to psychology and Iqbal in the international journals.

As a social contribution, Abbas joined the National Blood Bank (Pusat Darah Negara) in 1998 as a member and actively donates whole blood, plasma and platelets. As of June 2016, he has donated 318 times. He strongly believes that through the philosophy of sharing, caring and loving, humanity can create a better world

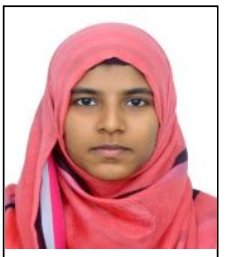

Hiba Ashraf is a Master student at the International Islamic University Malaysia. She obtained her B.Sc. (Hons) degree in Psychology from International Islamic University Malaysia in 2013. Then she taught for a while at Irshadiya College of Commerce and Social Sciences, Kerala, India before returning back to pursue her Master degree in the field of education specializing in social foundations of education.

She worked as research assistant to two projects funded by IIUM that conducted researches in the area of critical pedagogy and Multiculturalism. She Presented paper titled Social and Moral Implications of Authoritarian Interpretations of Texts at Islamic Academic Conference held in Kerala, India in January 2012. The paper was published in the conference proceedings. She also co-Presented paper titled Challenges Faced by Students in Islamization of Psychology: An IIUM Perspective at the 3rd conference of the International Association of Muslim Psychologists held at International Islamic University, Malaysia, in December 2011. 